\title{
IDENTIFIKASI ATRIBUT PELAYANAN DAN TINGKAT KEPUASAN KONSUMEN RUMAH MAKAN BAKSO DI LINGKUNGAN UNIVERSITAS LAMPUNG
}

\author{
(Identification Service's Attributes and Consumer Satisfaction of Meat Ball Restaurant \\ Surrounding the University of Lampung)
}

Magdalena Meiliani, Yaktiworo Indriani, Zainal Abidin

\begin{abstract}
Jurusan Agribisnis, Fakultas Pertanian, Universitas Lampung, Jl. Prof. Dr. Soemantri Brojonegoro No.1 Bandar Lampung 35141, Telp. 085383061839, e-mail: yaktiworo.indriani@fp.unila.ac.id
\end{abstract}

\begin{abstract}
The aims of this research are to analyze customer's characteristics, attributes of meatball and services, customer satisfaction; in addition to aplication of attributes and services of meatball restaurant. The data was collected in Januari-Maret 2018. The research location was determined purposively at Restaurant A, $B$ and $C$, surrounding The university of lampung (Unila). The technique used for sampling was accidental sampling, involving 99 students as respondents. Data was analyzed descriptively by Customer Satisfaction Index (CSI) and Importance Performance Analysis (IPA). The result showed that the consumers were mostly women students at Unila, 21-23 years old of age, having pocket money of Rp500,000 to 1,000,000 per month. The identified meatball attributes were taste, aroma, size of bowl, display of meatball, price, product guarantee, service alertness, service justice, availability of parking area, accessibility of location, cleanliness and employee hospitality. Consumer satisfaction value at Restaurant A, B, C was 70.20\%; $71.80 \%$ and $67.80 \%$ respectively; it meant that customers were satisfied. The attributes needed to be improved at Restaurant A were product guarantee and employee hospitality, while at Restaurant $B$ were price, service justice, service alertness, and employee patience.
\end{abstract}

Key words: attributes, CSI, IPA, meatball, satisfaction

\section{PENDAHULUAN}

Budaya masyarakat mungkin berubah seiring dengan perkembangan zaman. Menurut Sumarwan (2011) budaya merupakan segala nilai, pemikiran dan simbol, kepercayaan dan kebiasaan seseorang dan masyarakat Aktivitas pekerjaan di luar rumah yang semakin padat membuat masyarakat memilih membeli dan mengonsumsi makanan di luar, ini salah satu yang menyebabkan adanya perubahan gaya hidup masyarakat.

Kesibukan masyarakat kota yang meningkat menyebabkan tidak ada waktu yang cukup untuk menyiapkan makanan untuk dimakan di rumahnya termasuk bagi mahasiswa maupun pelajar (Bangun, Indriani, dan Soelaiman 2017). Makanan yang dikonsumsi seseorang disesuaikan dengan pendapatan, selera, dan tempat yang terjangkau. Pengeluaran rata-rata per kapita sebulan untuk makanan pada tahun 2016 di Kota Bandar Lampung sebesar Rp541.887,02 tertinggi di Provinsi Lampung (BPS Kota Bandar Lampung 2016).

Perkembangan usaha kuliner di Kota Bandar Lampung berprospek tinggi. Menurut Dinas
Kebudayaan dan Pariwisata Kota Bandar Lampung (2015), jumlah usaha rumah makan memiliki angka yang paling besar dibandingkan jenis usaha lainnya yaitu sebesar 192 rumah makan. Angka ini mengalami peningkatan dari tahun 2014 yang sebelumnya berjumlah 187 rumah makan. Meningkatnya pertumbuhan usaha kuliner di Bandar Lampung didukung oleh meningkatnya pendapatan masyarakat, bertambahnya jumlah penduduk, dan perkembangan teknologi yang membuat banyak inovasi yang dilakukan pemilik usaha terhadap jenis makanan yang ditawarkan.

Jumlah usaha kuliner yang semakin meningkat menunjukkan peluang usaha yang baik bagi pelaku usaha untuk memulai usahanya dan berkompetisi untuk memenangkan pangsa pasar. Rumah makan bakso merupakan salah satu jenis usaha kuliner yang diminati oleh banyak kalangan masyarakat sehingga menimbulkan daya tarik para pelaku usaha untuk berkompetisi. Salah satu kalangan yang menyukai jenis makanan ini adalah mahasiswa. Minat mahasiswa terhadap bakso cukup tinggi ditandai dengan terdapat beberapa rumah makan bakso yang berdiri dan ramai dikunjungi di sekitar lingkungan kampus seperti Kampus Universitas Lampung. 
Banyaknya usaha sejenis menimbulkan persaingan antara pelaku bisnis. Pelaku bisnis dapat menciptakan kesan yang baik pada konsumen terhadap produk yang ditawarkan dengan menjaga kualitas produk maupun kualitas pelayanan. Hal ini sangat mempengaruhi tingkat kepuasan konsumen pada produk yang ditawarkan.

Kepuasan konsumen merupakan hasil evaluasi tingkat perasaan seseorang terhadap suatu produk/jasa dengan membandingkan apa yang dirasakannya dengan yang diharapkan sebelumnya. Mengindentifikasi atribut pelayanan dan tingkat kepuasan konsumen merupakan suatu usaha penting untuk diketahui agar rumah makan mengetahui cara yang harus dilakukan oleh pihak rumah makan agar pelayanan yang diberikan kepada konsumen dapat memuaskan dan sesuai dengan kebutuhan atau keinginannya. Berdasarkan uraian tersebut, maka tujuan penelitian ini yaitu untuk mengetahui karakteristik, identifikasi atribut, tingkat kepuasan dan penerapan atribut dalam pembelian bakso di rumah makan bakso di lingkungan Universitas Lampung.

\section{METODE PENELITIAN}

Metode penelitian yang digunakan dalam penelitian ini adalah survai. Penelitian ini dilakukan di tiga rumah makan bakso yaitu RM Bakso A, B, dan C yang berada di Jalan Prof. Soemantri Brojonegoro (jalur dua unila) dan Jalan Bumi Manti (Kampung Baru). Responden penelitian ini adalah konsumen mahasiswa atau mahasiswi yang melakukan pembelian bakso di tiga rumah makan bakso di lingkungan Universitas Lampung. Penetuan jumlah sampel mengikuti pendapat Supranto (2006) bahwa jumlah sampel penelitian adalah lebih besar dari 30 dan kurang dari 500 responden. Penelitian ini menggunakan 99 responden yang terdiri dari 33 responden pada masing-masing RM. yang dipilih secara accidental sampling. Data yang digunakan dalam penelitian ini adalah data primer dan sekunder. Data primer merupakan data yang diperoleh dari hasil wawancara dengan konsumen menggunakan kuesioner seperti identitas responden, sedangkan data sekunder merupakan data lainnya yang dikumpulkan dari studi literatur, pustaka lain yang berhubungan dengan penelitian serta lembaga terkait seperti BPS Kota Bandar Lampung.

Kuesioner sebagai alat ukur berisi atribut-atribut kepuasan dan pelayanan konsumen. Atributatribut yang menjadi bahan pertimbangan responden dengan ketentuan untuk atribut pelayanan dan tingkat kepuasan konsumen terdapat 12 atribut yang terdiri dari cita rasa, aroma, porsi, tampilan penyajian, harga, jaminan produk, kesigapan pelayanan, keadilan pelayanan, ketersediaan area parkir, dan kemudahan akses lokasi, kebersihan, kesabaran karyawan.

Sebelum digunakan dalam penelitian, kuesioner diuji validitas dan reliabilitasnya. Berdasarkan hasil pengujian validitas dan reliabilitas dapat dilihat bahwa pada tingkat kepentingan dan tingkat kinerja, seluruh atribut valid dan reliabel karena nilai corrected item total correlation $>0,2$ (Surfen dan Natanael 2013) dan nilai cronbach alpa lebih besar dari 0,7 (Sugiyono 2008).

Data penelitian dianalisis deskriptif kuantitatif dan kualitatif. Analisis deskriptif kualitatif digunakan untuk mengetahui karakteristik konsumen. Analisis deskriptif kuantitatif digunakan dalam uji validitas, reliabilitas, IPA (Importance Performance Analysis), dan CSI (Customer Satisfaction Index).

Untuk mengidentifikasi atribut pelayanan dan tingkat kepuasan konsumen menggunakan analisis CSI dan IPA. Metode CSI merupakan metode yang digunakan untuk mengukur indeks kepuasan konsumen dari tingkat kepentingan dan tingkat kinerja. Skala likert merupakan indikator skala pengukuran kepuasan konsumen yang terdapat pada kuesioner. Tahapan dalam pengukuran CSI yaitu.

(1) Menghitung Weighted Factor (WF), yaitu mengubah nilai rata-rata kepentingan menjadi angka persentase dari total rata-rata tingkat kinerja seluruh atribut yang diuji.

(2) Menghitung Weighted Score (WS), yaitu nilai perkalian antara nilai rata-rata tingkat kinerja masing-masing atribut dengan WF masingmasing atribut.

(3) Menghitung Weighted Total (WT), yaitu menjumlahkan WS dari semua atribut jasa.

(4) Menghitung Satisfaction Index yaitu WT dibagi skala maksimum yang digunakan. Dalam penelitian ini skala maksimum yang digunakan adalah 5 kemudian dikalikan dengan $100 \%$.

Rentang skala dan interpretasi analisis CSI terdiri dari sangat tidak puas $(0,00-0,20)$; tidak puas $(0,21-0,40)$; cukup puas $(0,41-0,60)$; puas $(0,61-$ $0,80)$; dan sangat puas $(0,81-1,00)$ (Supranto 2006).

Metode Importance Performance Analysis (IPA) merupakan suatu teknik yang digunakan untuk 
mengukur atribut-atribut atau dimensi-dimensi dari tingkat kepentingan dengan tingkat kinerja yang diharapkan konsumen dan sangat berguna bagi pengembangan program strategi pemasaran yang efektif (Simamora 2002). Analisis ini dimasukkan untuk mengetahui keadaan masing-masing variabel dari faktor-faktor kepuasan yang ditinjau dari segi kinerja dan kepentingannya. Hasil analisis pada diagram kartesius terdiri dari 4 kuadran.

(1) Kuadran I (Prioritas utama)

Menunjukkan wilayah yang memuat faktorfaktor yang dianggap penting bagi konsumen, tetapi pada kenyataannya faktor-faktor ini belum sesuai dengan harapan pelanggan.

(2) Kuadran II (Pertahankan prestasi)

Menunjukkan wilayah yang memuat faktorfaktor yang dianggap penting oleh konsumen dan sudah dilakukan oleh rumah makan sehingga memberikan tingkat kepuasan yang relatif tinggi terhadap konsumen.

(3) Kuadran III (Prioritas rendah)

Menunjukkan wilayah yang memuat faktorfaktor yang dianggap kurang penting bagi konsumen dan pelaksanaannya pelayanan yang biasa saja oleh rumah makan.

(4) Kuadran IV (Berlebihan)

Menunjukkan wilayah yang memuat faktorfaktor yang dianggap kurang penting bagi konsumen, tetapi pelaksanaannya secara berlebihan oleh rumah makan sehingga mengakibatkan pemborosan.

\section{HASIL DAN PEMBAHASAN}

\section{Keadaan Umum Konsumen Rumah Makan Bakso}

Konsumen pada penelitian ini adalah mahasiswa. Karakteristik konsumen dibedakan berdasarkan asal universitas, jenis kelamin, usia, uang saku per bulan dan status tempat tinggal. Mayoritas konsumen RM Bakso A (85\%), RM B (85\%), dan RM C (94\%) adalah mahasiswa Universitas Lampung. Hal ini dikarenakan ketiga RM Bakso ini berdiri di lingkungan Kampus Unila. Konsumen bakso di RM Bakso A, B, dan C mayoritas berjenis kelamin perempuan. Konsumen RM Bakso A terdiri dari perempuan (85\%) dan laki-laki (15\%), RM Bakso B terdiri dari perempuan (67\%) dan laki-laki (33\%), RM Bakso $\mathrm{C}$ terdiri dari perempuan (82\%) dan laki-laki (18\%). Umur konsumen RM Bakso A, B, dan C adalah 21-23 tahun( 58\%, 70\%, dan 52\%). Hasil penelitian ini sejalan dengan penelitian Dianto (2013) yang menyatakan bahwa konsumen yang berumur $<25$ tahun memiliki kebiasaan makan di luar rumah. Hal ini dikarenakan usia produktif lebih banyak melakukan aktivitas di luar rumah. Sebagian besar konsumen di RM Bakso A (45\%), B (39\%), dan C (58\%) memiliki uang saku sebesar Rp500.000-<1.000.000 per bulan. Mayoritas konsumen RM Bakso A tinggal di rumah/tidak kos (67\%), sedangkan pada RM Bakso B dan C mayoritas konsumen tinggal di kos (61\% dan 85\%)

\section{Proses Pengambilan Keputusan dalam Pembelian Bakso di Rumah Makan Bakso}

Pengambilan keputusan dalam pembelian merupakan serangkaian kegiatan yang dilakukan oleh konsumen untuk memenuhi kebutuhannya. Tahapan dalam proses pengambilan keputusan yaitu pengenalan kebutuhan, pencarian informasi, evaluasi alternatif, keputusan pembelian dan perilaku pasca pembelian. Alasan utama dalam pembelian pada RM Bakso A yaitu rasa lapar $(60,61 \%)$, RM Bakso B yaitu rasa yang khas $(57,58 \%)$ dan RM Bakso C yaitu sekedar ingin mencoba $(57,58 \%)$. Pada saat konsumen tidak mengonsumsi produk RM Bakso A, B, dan $\mathrm{C}$ merasakan biasa saja dengan masing-masing persentase $(9,09 \% 12,12 \%$, dan $6,06 \%)$. Sumber informasi konsumen dalam pembelian pada RM Bakso A sebagian besar memperoleh informasi tentang rumah makan sendiri $(48,48 \%)$, sedangkan RM Bakso B dan C dari sebagian besar dari teman (36,36\% dan 48,48\%). Konsumen RM Bakso A dan $\mathrm{C}$ merasakan manfaat dari memgonsumsi bakso yaitu melepas rasa lapar $(48,48 \%$ dan $75,76 \%$ ), sedangkan RM Bakso B merasakan manfaat rasa enak dari bakso $(63,64 \%)$.

Konsumen merasakan perbedaan rumah makan bakso yang dikunjungi dengan RM bakso lainnya. Konsumen RM Bakso A merasa rumah makan ini memiliki tempat yang nyaman, sedangkan pada RM Bakso B dan C sebagian besar konsumen memilih RM tersebut bukan karena alasan kenyamanan. Alasan pemilihan pada RM Bakso B berupa rasa yang khas $(21,21 \%)$, enak $(9,09 \%)$, tekstur yang beda $(3,03 \%)$, murah $(6,06 \%)$, dan dekat kosan (3,03\%), sedangkan pada RM Bakso C terdiri dari dekat kosan $(36,36 \%)$, murah $(6,06 \%)$ dan enak $(3,03 \%)$.

Frekuensi konsumen dalam mengonsumsi bakso di RM Bakso A dan B adalah sebulan sekali $(42,42 \%$ dan 54,55\%), sedangkan pada konsumen RM Bakso $\mathrm{C}$ baru pertama kali mengonsumsi bakso $(45,45 \%)$. Mayoritas konsumen pada ketiga RM 
memilih datang berkunjung kembali ke RM dengan masing-masing persentase $(93,94 \% ; 100 \%$ dan $75,76 \%)$.

\section{Analisis Tingkat Kepuasan Konsumen}

\section{Customer Satisfaction Index (CSI)}

Customer Satisfaction Index (CSI) adalah metode yang digunakan untuk mengukur tingkat kepuasan konsumen secara keseluruhan dengan memperhatikan tingkat kepentingan dan tingkat kinerja. Metode ini menggunakan indeks angka yaitu dari angka satu yang menunjukkan bahwa konsumen sangat tidak puas hingga angka lima yang menunjukkan bahwa konsumen sangat puas. Perhitungan CSI pada penelitian ini secara lengkap disajikan pada Tabel 1.

Pada Tabel 1 dapat dilihat nilai CSI berada pada kriteria puas. Nilai CSI yang didapatkan pada masing-masing rumah makan tidak jauh berbeda. Hasil ini sejalan dengan penelitian yang dilakukan Prasetyowati, Hudoyo dan Rangga (2016) yang mana tingkat kepuasan konsumen RM satu lebih besar dibandingkan RM lainnya, namun skornya tidak jauh berbeda yaitu tetap berada pada kategori puas. Walaupun konsumen sudah merasa puas, RM Bakso A,B dan $\mathrm{C}$ harus lebih meningkatkan kinerjanya agar mencapai kategori sangat puas yaitu dengan rentang skala $81-100$ persen.

Dalam meningkatkan kepuasan konsumen, pihak rumah makan harus meningkatkan kinerja pada masing-masing atribut, terutama pada atribut yang memiliki angka Weighted Score (WS) paling rendah pada RM Bakso A yaitu aroma dan tampilan penyajian $(0,24)$, RM Bakso B yaitu tampilan penyajian dan harga $(0,24), \mathrm{RM}$ Bakso C yaitu katersediaan area parkir dan aroma $(0,17$; 0,21). Nilai WS rendah ketersediaan area parkir di RM Bakso C disebabkan oleh minimnya area parkir. Minimnya area parkir yang dimiliki tidak terlalu berpengaruh bagi konsumen. Hal ini dikarenakan mayoritas konsumen berjalan kaki.

Berdasarkan perhitungan CSI disimpulkan bahwa atribut produk dan atribut pelayanan yang memiliki nilai WS tertinggi pada ketiga RM adakah RM Bakso A yaitu atribut cita rasa dan kemudahan akses lokasi, RM Bakso B yaitu cita rasa, jaminan produk dan kebersihan, $\mathrm{RM}$ Bakso $\mathrm{C}$ adalah atribut cita rasa, keadilan pelayanan dan kesabaran karyawan dinilai baik dan memiliki kinerja yang baik sehingga mencapai kepuasan konsumen. Hal ini dibuktikan dari nilai WS cita rasa pada ketiga RM memiliki angka yang besar.

Nilai Weighted Score Total di RM Bakso A, B dan C masing-masing sebesar 3,51; 3,59 dan 3,39. Hasil tersebut didapatkan dari penjumlahan total Weighted Score seluruh atribut di rumah makan bakso. Tingkat kepuasan konsumen pada RM A, $\mathrm{B}$, dan $\mathrm{C}$ sudah memiliki nilai yang puas secara berturut-turut yaitu 70,20 persen; 71,80 persen dan 67,80 persen. Nilai diperoleh dari pembagian Weighted Score Total dengan skala maksimum, dikalikan 100 persen.

Kepuasan pelanggan merupakan indikator yang penting bagi keberhasilan usahanya, sehingga produsen perlu meningkatkan kinerjanya hingga mencapai kriteria puas. Hasil penelitian ini memiliki kesamaan dengan hasil penelitian Hasugian (2009) yang menyatakan bahwa nilai kepuasan konsumen Bakso Kota Cakman Bogor 24 jam secara keseluruhan adalah 72,54 persen sehingga konsumen berada pada kriteria puas.

Tabel 1. Perhitungan Customer Satisfaction Index (CSI) RM Bakso A, B, dan C

\begin{tabular}{|c|c|c|c|c|c|c|c|c|c|c|c|c|c|}
\hline \multirow[t]{2}{*}{ No } & \multirow{2}{*}{ Atribut } & \multicolumn{4}{|c|}{ RM Bakso A } & \multicolumn{4}{|c|}{ RM Bakso B } & \multicolumn{4}{|c|}{ RM Bakso C } \\
\hline & & MIS & WF & MSS & WS & MIS & WF & MSS & WS & MIS & WF & MSS & WS \\
\hline 1 & Cita rasa & 4,67 & 0,09 & 3,82 & 0,34 & 4,58 & 0,09 & 3,97 & 0,34 & 4,82 & 0,09 & 3,45 & 0,31 \\
\hline 2 & Aroma & 3,91 & 0,08 & 3,18 & 0,24 & 4,30 & 0,08 & 3,64 & 0,29 & 4,03 & 0,08 & 2,85 & 0,21 \\
\hline 3 & Porsi & 4,12 & 0,08 & 3,15 & 0,25 & 4,33 & 0,08 & 3,12 & 0,25 & 4,21 & 0,08 & 3,24 & 0,26 \\
\hline 4 & Tampilan penyajian & 3,88 & 0,07 & 3,15 & 0,24 & 3,88 & 0,07 & 3,30 & 0,24 & 3,97 & 0,07 & 3,21 & 0,24 \\
\hline 5 & Harga & 4,30 & 0,08 & 3,30 & 0,27 & 4,58 & 0,09 & 3,06 & 0,26 & 4,55 & 0,09 & 3,42 & 0,29 \\
\hline 6 & Jaminan produk & 4,58 & 0,09 & 3,45 & 0,30 & 4,79 & 0,09 & 3,85 & 0,34 & 4,73 & 0,09 & 3,39 & 0,30 \\
\hline 7 & Kesigapan pelayanan & 4,42 & 0,09 & 3,27 & 0,28 & 4,61 & 0,09 & 3,55 & 0,30 & 4,48 & 0,08 & 3,70 & 0,31 \\
\hline 8 & Keadilan pelayanan & 4,36 & 0,08 & 3,55 & 0,30 & 4,61 & 0,09 & 3,52 & 0,30 & 4,48 & 0,08 & 3,91 & 0,33 \\
\hline 9 & Area parkir & 4,09 & 0,08 & 3,67 & 0,29 & 4,21 & 0,08 & 3,76 & 0,30 & 4,33 & 0,08 & 2,15 & 0,17 \\
\hline 10 & Akse & 4,42 & 0,09 & 4,12 & 0,35 & 4,24 & 0,08 & 3,97 & 0,31 & 4,39 & 0,08 & 3,91 & 0,32 \\
\hline 11 & Kebersiha & 4,85 & 0,09 & 3,67 & 0,34 & 4,94 & 0,09 & 3,79 & 0,35 & 4,85 & 0,09 & 3,45 & 0,31 \\
\hline \multirow[t]{3}{*}{12} & Kesabaran karyawan & 4,36 & 0,08 & 3,64 & 0,31 & 4,52 & 0,08 & 3,52 & 0,30 & 4,61 & 0,09 & 3,82 & 0,33 \\
\hline & & \multicolumn{4}{|c|}{ Total Score $=51,96$} & \multicolumn{4}{|c|}{ Total Score $=53,58$} & \multicolumn{4}{|c|}{ Total Score $=53,45$} \\
\hline & CSI & \multicolumn{4}{|c|}{$(3,51: 5) \times 100 \%=70,20 \%$} & \multicolumn{4}{|c|}{$(3,59: 5) \times 100 \%=71,80 \%$} & \multicolumn{4}{|c|}{$(3,39: 5) \times 100 \%=67,80$} \\
\hline
\end{tabular}


Importance Performance Analysis (IPA)

Importance Performance Analysis (IPA) merupakan metode yang menggambarkan kinerja dan harapan konsumen terhadap produk. Tingkat kepuasan dipengaruhi oleh kualitas produk sehingga dapat diketahui atribut yang seharusnya dipertahankan, diperbaiki, maupun ditingkatkan. Berdasarkan hasil perhitungan dalam metode CSI, ketiga RM masih harus meningkatkan kinerja usahanya agar dapat memperoleh hasil yang maksimal. Hal ini dapat ditingkatkan dengan meningkatkan kinerja pada masing-masing atributnya. Metode ini digunakan untuk mengetahui tingkat kepentingan dan kinerja dari tiap-tiap atribut. Rata-rata nilai kepentingan dan kinerja masing-masing-masing RM dapat dilihat pada Tabel 2. Hasil dari metode IPA yaitu diagram kartesius dapat dilihat pada Gambar 1.

Kuadran I merupakan daerah prioritas utama. Pada Gambar 1, dapat dilihat kuadran I, atribut yang terdapat pada RM Bakso A yaitu jaminan produk dan kesigapan pelayanan, RM Bakso B yaitu harga, keadilan pelayanan, kesigapan pelayanan, dan kesabaran karyawan, sedangkan pada RM Bakso $\mathrm{C}$ tidak terdapat atribut dalam kuadran ini. Hasil penelitian pada RM Bakso C sejalan dengan penelitian terdahulu Dianto (2013) yang tidak ada atribut pada kuadran I. Tidak terdapat atribut di dalam kuadran ini dapat diartikan konsumen sudah merasa puas dengan pelayanan atribut yang diberikan oleh RM Bakso C. Hal ini dapat disebabkan perbedaan standar rumah makan menurut konsumen yang berbeda dengan RM Bakso A dan B. RM Bakso C terletak di sekitar kos mahasiswa dan mayoritas konsumen merupakan anak kos $(85 \%)$.

Kuadran II merupakan daerah pertahankan prestasi. Atribut yang berada pada RM Bakso A yaitu cita rasa, keadilan pelayanan, kemudahan akses lokasi, kebersihan, dan kesabaran karyawan, RM Bakso B yaitu cita rasa, jaminan produk, dan kebersihan, serta RM Bakso C yaitu cita rasa, harga, jaminan produk, kesigapan pelayanan, keadilan pelayanan, kebersihan dan kesabaran karyawan. Atribut ini memiliki nilai WS yang tinggi pada perhitungan CSI yang berarti bahwa atribut tersebut sudah dapat memberikan rasa puas terhadap konsumen dan harus dipertahankan oleh rumah makan. Hasil penelitian pada ketiga RM serupa dengan penelitian terdahulu Aryanti, Hudoyo dan Kasymir (2013) bahwa atribut cita rasa berada pada kuadran ini. Atribut tersebut dinilai penting oleh konsumen dan sudah dapat memuaskan konsumen.

Kuadran III merupakan daerah prioritas rendah. Atribut pada kuadran ini di RM Bakso A adalah aroma, porsi, tampilan penyajian, dan harga. RM Bakso B adalah porsi dan tampilan penyajian, sedangkan RM Bakso $\mathrm{C}$ adalah aroma, porsi, tampilan penyajian, dan ketersediaan area parkir. Atribut kuadran III memiliki nilai WS terendah pada perhitungan CSI. Hal ini berarti bahwa konsumen tidak begitu mementingkan atribut dalam kuadran ini dan pelaksanaan pada rumah makan juga biasa saja.Konsumen tidak terlalu membutuhkan area parkir dikarenakan mayoritas konsumen (anak kos) yang dekat dengan kosannya dan tidak memiliki kendaraan (jalan kaki).

Kuadran IV merupakan daerah berlebihan sehingga mengakibatkan pemborosan. Pada RM Bakso A, atribut yang berada pada kuadran ini adalah ketersediaan area parkir, RM Bakso B adalah aroma, ketersediaan area parkir, dan kemudahan akses lokasi, RM Bakso C adalah atribut kemudahan akses lokasi. Berdasarkan penelitian Putriana (2010) bahwa atribut kemudahan akses lokasi terdapat di kuadran IV. Konsumen merasa dengan kinerja yang tidak berlebihan, konsumen merasa puas.

\section{KESIMPULAN}

Berdasarkan hasil penelitian disimpulkan bahwa konsumen bakso di RM Bakso A, B, dan C sebagian besar berasal dari Universitas Lampung, berjenis kelamin perempuan dengan rentang usia 21-23 tahun dan memiliki uang saku sekitar Rp500.000 - $<1.000 .000$ per bulan. Konsumen RM Bakso A sebagian besar tinggal di rumah (tidak kos), sedangkan konsumen RM Bakso B dan C mayoritas merupakan anak kos. Atribut bakso yang diinginkan oleh konsumen di lingkungan Unila adalah citarasa, aroma, porsi, tampilan penyajian, harga, dan jaminan produk, sedangkan atribut pelayanan adalah kesigapan pelayanan, keadilan pelayanan, ketersediaan area parkir, kemudahan akses lokasi, kebersihan, dan kesabaran karyawan. Tingkat kepuasan konsumen pada RM Bakso A, B, dan C adalah puas terhadap kinerja yang diberikan oleh ketiga RM tersebut. Atribut yang perlu ditingkatkan kinerjanya pada RM Bakso A adalah jaminan produk dan kesigapan pelayanan, RM Bakso B adalah harga, keadilan pelayanan, kesigapan pelayanan, dan kesabaran karyawan, sedangkan RM Bakso C tidak ada. 
JIIA, VOLUME 7 No. 2, MEI 2019

Tabel 2. Tingkat kepentingan dan tingkat kinerja atribut

\begin{tabular}{|c|c|c|c|c|c|c|}
\hline \multirow{2}{*}{ Atribut } & \multicolumn{2}{|c|}{ RM Bakso A } & \multicolumn{2}{|c|}{ RM Bakso B } & \multicolumn{2}{|c|}{ RM Bakso C } \\
\hline & $\mathrm{Y}$ & $\mathrm{X}$ & $\mathrm{Y}$ & $\mathrm{X}$ & $\mathrm{Y}$ & $\mathrm{X}$ \\
\hline Cita rasa & 4,67 & 3,82 & 4,58 & 3,97 & 4,82 & 3,45 \\
\hline Aroma & 3,91 & 3,18 & 4,30 & 3,64 & 4,03 & 2,85 \\
\hline Porsi & 4,12 & 3,15 & 4,33 & 3,12 & 4,21 & 3,24 \\
\hline Tampilan penyajian & 3,88 & 3,15 & 3,88 & 3,30 & 3,97 & 3,21 \\
\hline Harga & 4,30 & 3,30 & 4,58 & 3,06 & 4,55 & 3,42 \\
\hline Jaminan produk & 4,58 & 3,45 & 4,79 & 3,85 & 4,73 & 3,39 \\
\hline Kesigapan pelayanan & 4,42 & 3,27 & 4,61 & 3,55 & 4,48 & 3,70 \\
\hline Keadilan pelayanan & 4,36 & 3,55 & 4,61 & 3,52 & 4,48 & 3,91 \\
\hline Ketersediaan area parkir & 4,09 & 3,67 & 4,21 & 3,76 & 4,33 & 2,15 \\
\hline Kemudahan akses lokasi & 4,42 & 4,12 & 4,24 & 3,97 & 4,39 & 3,91 \\
\hline Kebersihan & 4,85 & 3,67 & 4,94 & 3,79 & 4,85 & 3,45 \\
\hline Kesabaran karyawan & 4,36 & 4,12 & 4,52 & 3,52 & 4,61 & 3,82 \\
\hline Rata-rata $(\mathrm{X}, \mathrm{Y})$ & 4,33 & 3,49 & 4,46 & 3,59 & 4,45 & 3,38 \\
\hline
\end{tabular}

\section{Keterangan:}

$\mathrm{X}=$ Tingkat kinerja atribut

$\mathrm{Y}=$ Tingkat kepentingan atribut

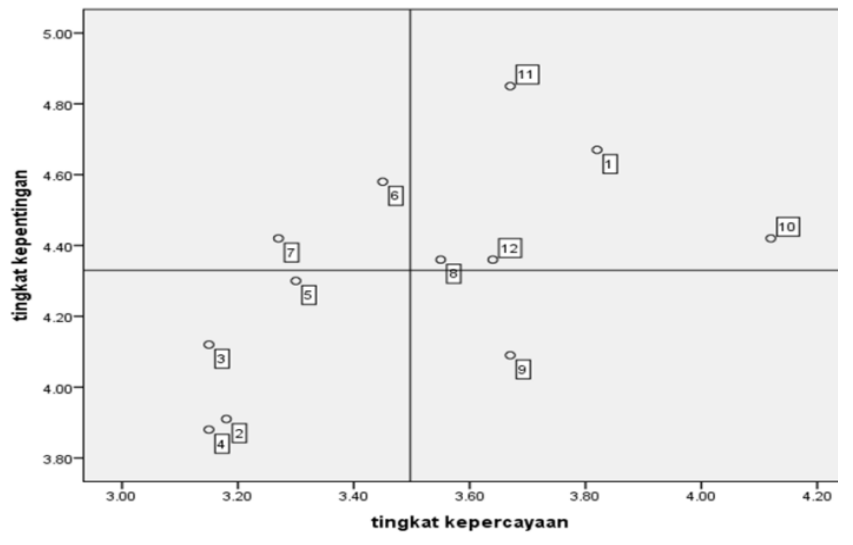

RM Bakso A

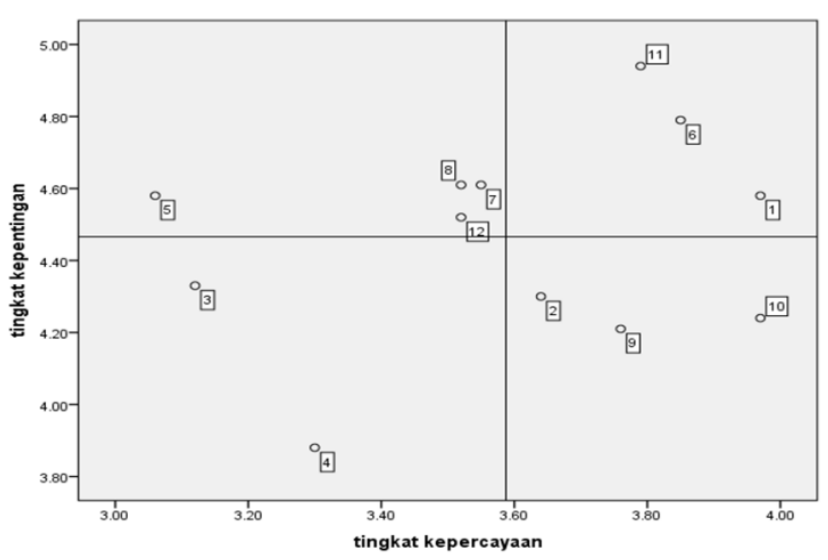

RM Bakso B

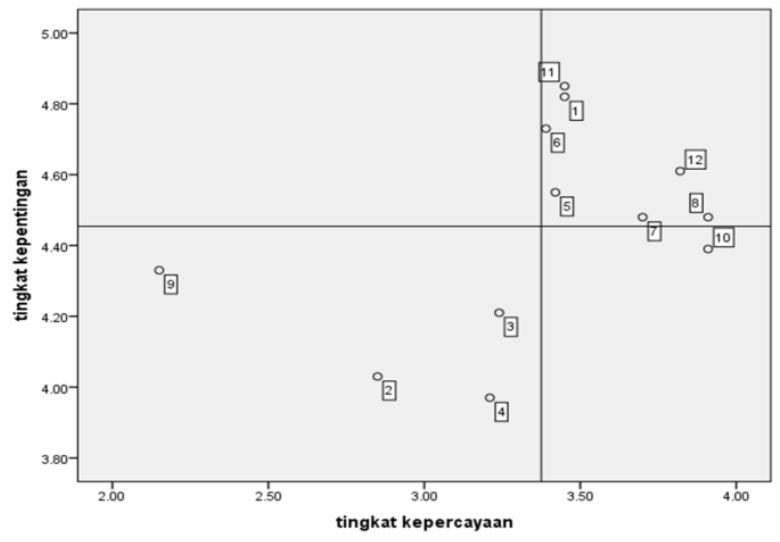

RM Bakso C

Keterangan :
1. Cita rasa
2. Aroma
3. Porsi
4. Tampilan penyajian
5. Harga
6. Jaminan produk
7. Kesigapan pelayanan
8. Keadilan pelayanan
9. Ketersediaan area parkir
10. Kemudahan akses lokasi
11. Kebersihan
12. Kesabaran karyawan

Gambar 1. Diagram kartesius Importance Performance Analysis (IPA) pada RM Bakso A, B dan C 


\section{DAFTAR PUSTAKA}

Aryanti D, Hudoyo A, Kasymir E. 2013. Analisis tingkat pelayanan restoran terhadap kepuasan pelanggan: studi kasus pada dua restoran di kompleks pertokoan Way Halim Permai Kota Bandar Lampung. JIIA 1(2): 118-125. http://jurnal.fp.unila.ac.id.index.php//JIA/artic le/view/238. [1 November 2017].

Badan Pusat Statistik Kota Bandar Lampung. 2016. Kota Bandar Lampung Dalam Angka. BPS Kota Bandar Lampung. Bandar Lampung.

Bangun YF, Indriani Y, dan Soelaiman A. 2017. Sikap dan kepuasan konsumen Rumah Makan Ayam Penyet Hang Dihi Bandar Lampung. JIIA 5(1):101-108. http://jurnal.fp.unila.ac.id /index.php/JIA/article/view/1680/1506. [3 November 2017].

Dianto IW. 2013. Analisis Kepuasan Konsumen Waroeng Steak and Shake Jl. Cendrawasih No. 30 Yogyakarta. Skripsi. Jurusan Manajemen. Fakultas Ekonomi. Universitas Negeri Yogyakarta. [5 November 2017].

Dinas Kebudayaan dan Pariwisata Kota Bandar Lampung. 2015. Jumah Jenis Usaha. Bandar Lampung.

Hasugian H. 2009. Analisis Perilaku Konsumen Terhadap Warung Bakso Kota Cakman Bogor Buka 24 Jam. Skripsi. Departemen Agribisnis. Fakultas Ekonomi dan
Manajemen. Institut Pertanian Bogor. [5 November 2017]

Prasetyowati A, Hudoyo A, dan Rangga KK. 2016. Identifikasi atribut kepuasan konsumen dan pelayanan rumah makan olahan ayam di Kota Bandar Lampung. JIIA 4(4): 384-390. http://jurnal.fp.unila.ac.id/index.php.JIA.articl e/view/1520. [3 November 2017]

Putriana RR. 2010. Analisis Kepuasan dan Loyalitas Konsumen Midori Japanese Restaurant Cabang K.H. Wahid Hasyim Jakarta Pusat. Skripsi. Departemen Agribisnis. Fakultas Ekonomi dan Manajemen. Institut Pertanian Bogor. [5 November 2017]

Simamora B. 2002. Panduan Riset Perilaku Konsumen. PT Gramedia Pustaka Utama. Jakarta.

Sugiyono. 2008. Pengertian Uji Validitas dan Uji Reliabilitas Pada Kuisioner. Intermedia. Jakarta.

Sumarwan U. 2011. Perilaku Konsumen: Teori dan Penerapannya dalam Pemasaran. PT Ghalia Indonesia. Jakarta.

Supranto J. 2006. Pengukuran Tingkat Kepuasan Pelanggan.

Surfen dan Nathanael Y. 2013. Mahir Menggunakan SPSS Secara Otodidak. Gramedia. Jakarta. 